\title{
Rapid extraction of DNA suitable for NGS workflows from bacterial cultures using the PDQeX
}

Jo-Ann L Stanton*,1 , Abishek Muralidhar², Christy J Rand' \& David J Saul²

\section{ABSTRACT}

Background: PDQeX is a novel, singlestep DNA extraction method that purifies nucleic acid from sample in under $30 \mathrm{~min}$. Materials \& Methods: Six bacterial suspensions from species with different cell morphologies and growth optima were made. DNA from half the suspension was purified using PDQeX and the other half using a conventional column purification method. Sequencing and analyses using Ion PGM were performed, blinded to extraction method and species. Results: Genomes extracted with either method sequenced successfully. No significant sequence distribution biases were evident between PDQeX and column purification. Surveyed community preference suggested comparable performance between the two extraction methods. Conclusion: DNA prepared using the PDQeX performs as well for whole-genome sequencing as DNA purified using a conventional method, albeit much more rapidly.

\section{METHOD SUMMARY}

We introduce the PDQeX: a new, rapid, single-step method for DNA extraction that is compatible with high-throughput sequencing. Sample is added to the thermoresponsive PDQeX extractor tube with a cocktail of thermostable enzymes. Upon incubation and heating the extracted DNA is expelled into a collection tube ready for use in downstream applications in under $30 \mathrm{~min}$.

\section{KEYWORDS:}

bacterial DNA preparation - DNA extraction - genome sequencing • Ion PGM • PDQeX - QIAGEN DNeasy - whole-genome sequencing $\cdot$ ZyGEM

'Department of Anatomy, University of Otago, $P O$ Box 56, Dunedin 9054, New Zealand; '2ZyGEM NZ Ltd, Waikato Innovation Park, Ruakura Road, Hamilton 3216, New Zealand; *Author for correspondence: jo.stanton@otago.ac.nz

BioTechniques 66: 208-213 (May 2019) 10.2144/ btn-2019-0006
The PDQeX system uses a radically different approach to DNA extraction compared with current laboratory methods. It harnesses activities from a range of enzymes extracted from extremophiles coupled with thermoresponsive plastics to extract DNA from samples without the use of centrifugation or harsh solvents. This system has already been demonstrated for PCR, qPCR and STR analysis in human tissue samples [1]; however, it was unknown whether it was compatible with high throughput sequencing. This uncertainty rests on two aspects of the PDQeX system. First, the final extrusion step heats the sample to $95^{\circ} \mathrm{C}$; potentially denaturing DNA. Second, buffer components required by the PDQeX process remain in the DNA sample. These buffer components distort 260/230 and $260 / 280$ ratios used as traditional measures of DNA purity.

The PDQeX is a three-component system combining a powerful enzymedriven extraction chemistry [2] with an innovative extractor cartridge and a temperature control unit [3]. The extraction chemistry consists of a cocktail of thermophilic proteinases and mesophilic cell wall degrading enzymes that systematically lyse cells, destroy nucleases, digest proteins and release nucleic acids. The extractor cartridges, made from thermo-responsive polymers, not only facilitate extraction but also remove enzyme inhibitors from extracts (Figure 1). The temperature-controlled extraction is performed in a chamber at the top of the cartridge. The temperature used to activate the protease also leads to a pressure increase in the closed tube, forcing the extract through a heat-burstable valve and a proprietary purification matrix housed at the bottom of the cartridge. The purification segment removes cell debris, inhibitory polyphenols and polysaccharides. This single-step closed system setup allows for rapid, hands-free preparations of DNA without the danger of cross-contamination.

A side-by-side whole-genome sequencing comparison of DNA prepared using the PDQeX and a standard column method, QIAGEN DNeasy, was proposed. Six thermophilic aerobes with varied cell wall morphologies and growth optima were chosen from the ZyGEM NZ Ltd culture collection. Meiothermus ruber, Thermus sp. and Thermus filiformis are Gram-negative. Two Geobacillus sp. and Alicyclobacillus sp. are Gram-positive. Alicyclobacillus is also an acidophile with optimal growth at $\mathrm{pH} 3$. All other strains grew optimally above $\mathrm{pH}$. All sequencing and analyses were performed blind to both extraction method and bacterial species to prevent unconscious bias.

\section{MATERIALS \& METHODS}

\section{Selection, growth \& maintenance of}

\section{bacterial cultures}

Details for each of the bacteria used in this study are given in Table 1. All chemicals were sourced from Sigma Aldrich unless specified otherwise. Strain ZCC225 Alicyclobacillus sp. was grown on Brock's acid medium ( $\mathrm{g} / \mathrm{l}$ distilled water), starch (soluble) $2 \mathrm{~g}$, yeast extract $2 \mathrm{~g}$, $(\mathrm{NH} 4)_{2} \mathrm{SO}_{4} 0.2 \mathrm{~g}, \mathrm{MgSO}_{4} .7 \mathrm{H}_{2} \mathrm{O} 0.5 \mathrm{~g}$, $\mathrm{CaCl}_{2} \cdot 2 \mathrm{H}_{2} \mathrm{O} 0.25 \mathrm{~g}, \mathrm{KH}_{2} \mathrm{PO}_{4} 3 \mathrm{~g}$, $\mathrm{FeSO}_{4} \cdot 7 \mathrm{H}_{2} \mathrm{O} 0.28 \mathrm{mg}, \mathrm{MnCl}_{2} \cdot 4 \mathrm{H}_{2} \mathrm{O} 1.25 \mathrm{mg}$, $\mathrm{ZnSO}_{4} .7 \mathrm{H}_{2} \mathrm{O} 0.4 \mathrm{mg}$. Ingredients were dissolved in $900 \mathrm{ml}$ distilled water, $\mathrm{pH}$ adjusted to 3 with $1 \mathrm{M} \mathrm{H}_{2} \mathrm{SO}_{4}$ and autoclaved. Gelrite (Gelzan'" CM) $20 \mathrm{~g}$ was sterilized separately in $100 \mathrm{ml}$ distilled water and added to the media once cooled to $50^{\circ} \mathrm{C}$ to prevent acid hydrolysis. The other strains were grown on Tryptic Soy Broth (Becton, Dickinson and Co., NJ, USA) amended with $2 \%$ Gelrite.

Strains were grown from glycerol stocks by plating onto Petri dishes incubated at the respective optimal temperatures (Table 1). Petri dishes 


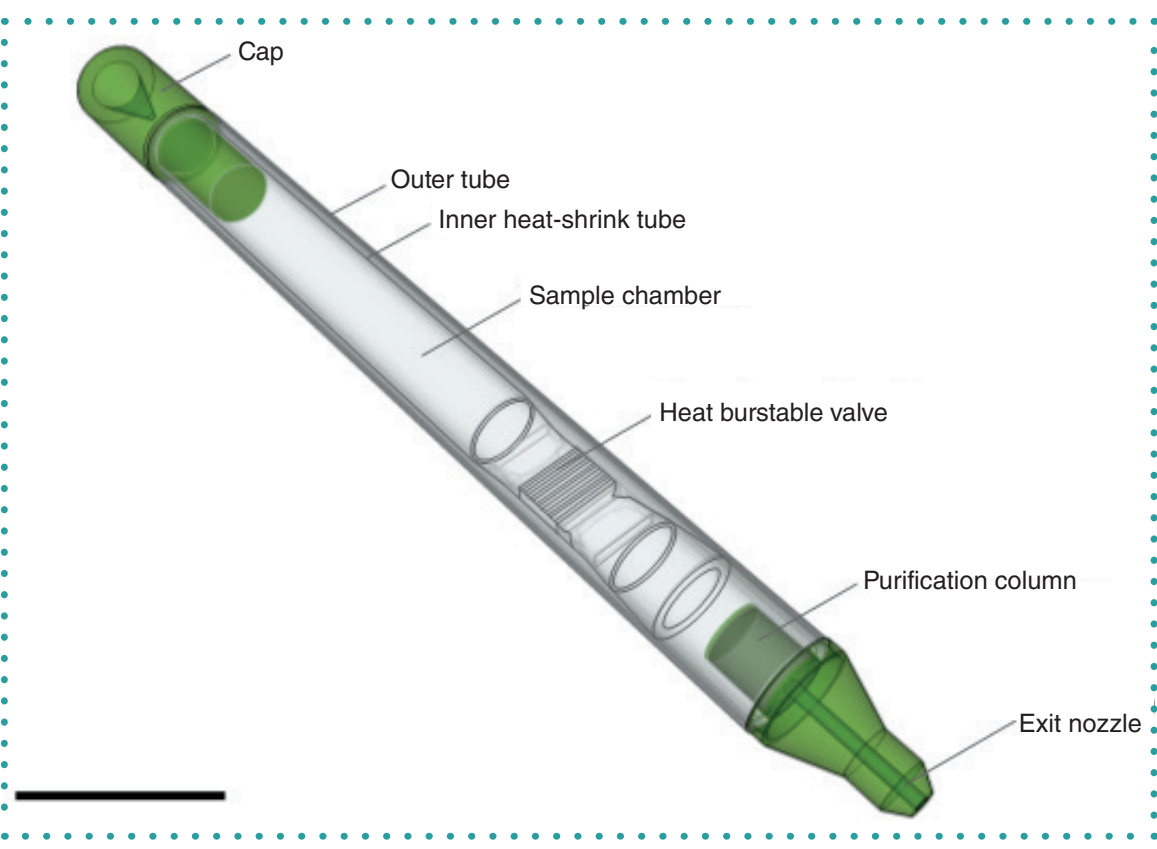

Figure 1. Illustration showing different components of the PDQeX extractor cartridge. The PDQeX extractor cartridge is placed in the separate temperature control unit when in use. Scale bar: $\sim 10 \mathrm{~mm}$.

Dere sealed with cling film and placed in zip-lock bags with a moist paper towel to prevent drying. 5-day-old growths were used for DNA extraction because some strains grew slower than others.

\section{DNA EXTRACTION \& QUANTIFICATION}

\section{Sample preparation}

Two sterile inoculation loops $\left(\sim 3 \mathrm{~mm}^{2}\right.$ each $)$ of plated culture were resuspended in $200 \mu \mathrm{l}$ of ultrapure water in a $1.5-\mathrm{ml}$ microcentrifuge tube and mixed by pipetting. Half of the bacterial suspension $(100 \mu \mathrm{l})$ was used for the PDQeX bacterial extraction protocol and the other used for the QIAGEN DNeasy Blood and Tissue kit (QIAGEN, Hilden, Germany) bacterial extraction protocol, ensuring that the same amount of starting material was used for both protocols.
Reagents and chemicals described below are proprietary formulations of ZyGEM NZ Ltd and QIAGEN Ltd.

\section{DNA extraction using the PDQeX protocol}

The PDQeX Bacteria kit from ZyGEM NZ Ltd was used as per manufacturer's instructions. Briefly, to $100 \mu$ l culture, $400 \mu$ l of $1 x$ WASH Buffer was added and vortexed vigorously to disperse cells. The WASH buffer reduces polysaccharides and prewashing improves extractions from capsulated bacteria and bacteria producing exopolysaccharides. The cells were centrifuged at 10,000 rcf for 5 minutes and all the supernatant was removed. The pellet was resuspended in extraction mix: $10 \mu$ l of 10x GREEN PLUS buffer, $2 \mu$ l of prepGEM, $2 \mu \mathrm{l}$ of Lysozyme (10 $\left.\mathrm{mg} \mathrm{ml}^{-1}\right)$ made up to $100 \mu \mathrm{l}$ with ultrapure water. Lysozyme can be omitted for Gram-negatives but was included for all the strains in this study. The extraction mixture was dispensed into PDQeX extractor cartridges and run through the following protocol in the PDQeX 2400 device: $37^{\circ} \mathrm{C}$ for $5 \mathrm{~min}, 75^{\circ} \mathrm{C}$ for $5 \mathrm{~min}$ and $95^{\circ} \mathrm{C}$ for $2 \mathrm{~min}$. At the end of the program, extracts containing purified bacterial DNA were collected in 0.2-mI PCR tubes in the PDQeX collection tray. Extracted DNA was adjusted to 1xTE buffer (10 mM Tris, pH 7.5, 1 mM EDTA) and stored at $4^{\circ} \mathrm{C}$.

\section{DNA extraction using the QIAGEN protocol}

The bacterial DNA extraction protocol described in the QIAGEN DNeasy Blood and Tissue handbook was followed without deviations. For Gram-positive strains, $100-\mu$ l cultures were centrifuged for $10 \mathrm{~min}$ at $6000 \mathrm{rcf}$ and the pellet resuspended in 180- $\mu$ l enzymatic lysis buffer (20 mM Tris-Cl pH 8, 2 mM Na EDTA, 1.2\% Triton ${ }^{\circledR} \mathrm{X}-100$, Lysozyme $20 \mathrm{mg} / \mathrm{ml}$ ). This was incubated for $30 \mathrm{~min}$ at $37^{\circ} \mathrm{C}$. For Gram-negative strains, the pellet was resuspended in the $180 \mu \mathrm{l}$ of ATL buffer. $25 \mathrm{ml}$ of Proteinase $\mathrm{K}$ and $200 \mu \mathrm{l}$ of $\mathrm{AL}$ buffer were added to the samples, mixed and incubated for $30 \mathrm{~min}$ at $56^{\circ} \mathrm{C}$. To this was added $200 \mu \mathrm{l}$ of $100 \%$ ethanol. The mix was vortexed and transferred into a DNeasy Mini spin column placed in a collection tube, followed by centrifugation for $1 \mathrm{~min}$ at 6800 rcf. The column was then washed with $500 \mu \mathrm{l}$ AW1 and then $500 \mu \mathrm{l}$ AW2 buffers, centrifuging each time for $1 \mathrm{~min}$ at $6800 \mathrm{rcf}$. The column was placed in a sterile Eppendorf tube, $100 \mu \mathrm{AE}$ buffer added and centrifuged for $1 \mathrm{~min}$ at $6800 \mathrm{rcf}$ to elute purified bacterial DNA.

\begin{tabular}{|l|l|l|l|l|l|l|}
\hline \multicolumn{2}{|l}{ Table 1. Strain numbers, collection locations, species ID and growth optima of strains used in this study. } \\
\hline Strain \# & \multicolumn{1}{|l}{ Collection \# } & Location & \multicolumn{2}{c|}{ Species } & Gram +/- & Optimal pH/temperature ( ${ }^{\circ}$ C) \\
\hline ZCC225 & WP 18 A.1 & Waiotapu, New Zealand & Alicyclobacillus sp. & + & $3 / 60$ \\
\hline ZCC142 & Mk 22 A.1 & Mokai, New Zealand & Geobacillus sp. & + & $7.6 / 70$ \\
\hline ZCC17 & Ok 4.A1 & Orakei Korako, New Zealand & Thermus filiformis & - & $7.6 / 70$ \\
\hline ZCC16 & Fj 3.A1 & Savu Savu Beach, Fiji & Geobacillus sp. & + & $7.6 / 70$ \\
\hline ZCC14 & Rt 4.A1 & Rotorua, New Zealand & Thermus sp. & - & $7.6 / 70$ \\
\hline ZCC12 & Wai 35.A1 & Waimangu, New Zealand & Meiothermus ruber & - & $7.6 / 50$ \\
\hline
\end{tabular}




\section{DNA quality assessment}

\section{\& quantification}

To assess quality of the DNA, electrophoresis of extracts was carried out on $2 \%$ Agarose (Bioline Ltd, London, UK) in 1x TBE buffer (Duchefa Biochemie, Haarlem, The Netherlands) (Supplementary Figure 1). Quantification of the extracts was carried out using the fluorometric iQuant ${ }^{\mathrm{m}}$ High Sensitivity dsDNA quantification kit following manufacturer's instructions (GeneCopoeia Inc., MD, USA). Six pairs of extracts were selected based on longest fragment length integrity coupled with highest DNA concentration. Samples were coded to blind the sequencing team to extraction method, species and strain. All samples were sent from Hamilton (North Island, New Zealand) to Dunedin (South Island, New Zealand) as a single shipment. On arrival, samples were re-checked for integrity using 2\% agarose $\mathrm{E}-\mathrm{Gel}$ (Cat\#G501802, Invitrogen), and DNA concentrations determined using the Qubit dsDNA HS Assay Kit (Cat\# Q32851, Invitrogen).

\section{Ion Xpress Library preparation}

DNA was fragmented using the Ion Shear Plus Reagent as per manufacturer's instructions. Sequencing libraries were prepared using the Ion Xpress Plus gDNA Fragment Library protocol with E-gel Size-Select II Agarose Gel 2\% size-selection (Cat\#G661012, Invitrogen), the Ion Xpress Plus Fragment Library Kit (\#4471269, Life Technologies) and Ion Xpress Barcode Adapters (\#4471250, Life Technologies). 100 ng starting material was used for all samples except sample 2, which used 84 ng due to its low concentration. The concentration, yield and fragment size distribution of all 12 prepared DNA libraries were checked using a High Sensitivity DNA assay on the Agilent 2100 Bioanalyser (Agilent Technologies, CA, USA).

Three barcodes were used between all 12 sample libraries. Pooled sets of three barcoded libraries were sequenced on four separate runs on the Ion PGM sequencing platform (Life Technologies) using the following kits: ION PGM Hi-Q View OT2 kit (Cat\# A29900); ION PGM Hi-Q View sequencing kit (Cat\# A30044); Ion 316 chip kit v2 BC (Cat\# 4488149). The Ion PGM performed 850 flows for each run.

\section{Data analysis}

Sequence from each barcoded library was separated into different data files automatically on the Ion PGM. Sequence read quality was evaluated using FastQC v 0.113 (www. bioinformatics.babraham.ac.uk/projects/ fastqc/) and the FASTX-toolkit v 0.0.14 (http://hannonlab.cshl.edu/fastx_toolkit/ index.html) was used to remove potential adaptor sequences with a read length $<50 \mathrm{bp}$, and any low-quality reads containing $<40 \%$ of bases with a Phred score of $\geq 25$. All reads that remained following quality filtering were de novo assembled using Geneious v 9.1.5. Contigs generated from the assemblies were analyzed by BLAST using NCBI (www.ncbi. nlm.nih.gov) to give a list of the most closely related bacterial reference sequences in GenBank. In a second analysis, quality filtered sequence reads were mapped to each bacterial reference sequence. Read length data were statistically analyzed with one-way ANOVA, while number of sequence counts were analyzed with Poisson regression using the software package Stata.

\section{RESULTS \& DISCUSSION}

A total of 18 bacterial genomic DNA extractions using both methods were performed simultaneously: six strains extracted in triplicate (Supplementary Figure 1). Using the PDQeX method, the full protocol including prewash and a single transfer step took under 30 mins. The whole extraction was performed in a closed extractor cartridge with no handling of sample post preparation. By contrast, the QIAGEN bacterial extraction method took over $2 \mathrm{~h}$, including two incubations and several pipetting, transfer and centrifugation steps, increasing the possibility of contamination (Figure 2).

Six pairs of DNA samples, one from each extraction method and species, were coded and sent to the sequencing team located in a different city, for lon PGM sequencing (Table 2). At the time of sequencing and analysis, the sequencing team only knew the sample code number and were blind to bacterial species and extraction method. DNA fragment libraries were constructed from each sample and lon PGM sequencing performed. Four pools of three barcoded libraries were sequenced on a total of four Ion $316 v 2$ chips. This limited the number of barcodes used across the experiment with equal numbers of libraries constructed from either PDQeX or QIAGEN tagged with each barcode.

Library and sequence run metrics are given in Table 3 (datasets available on request). The mean read length for each library ranged from 234 to $273 \mathrm{bp}$ and the number of quality filtered reads ranged from 423,677 for sample 2 to $2,195,989$ for sample 1. Between 95 and $98 \%$ of raw reads remained post quality filtering, testament to the raw sequence data quality. Although the sample size was small, a Poisson regression analysis suggested there was a barcode-introduced bias in the number of sequence counts ( $p<0.001)$. This suggested bias did not extend to sequence data quality as represented by the lack of statistical difference in sequence read length between libraries and barcodes (Supplementary Table 1).

Geneious de novo assembly statistics are given in Table 4. All sequence data files could be assembled except Sample 1. The longest contig of each assembled genome was BLAST searched against the NCBI database and sequence matches used to identify closest bacterial species (Table 2). Samples were paired based on match to the closest reference sequence. Five paired de novo assembly statistics were sent to two groups of genome scientists not associated with this project (Group A and B), who were asked to rank each pair of assemblies based on criteria they usually use for their own research projects. A weighted point-scoring system was used to assess which data set was scored as 'best'. QIAGEN-extracted DNA was scored as 'best' for two bacteria and three were scored 'best' for the PDQeX (Table 4). Unweighted preference scores are given in Supplementary Table 2.

Coverage depth and sequence distribution were evaluated by mapping each of the 12 data sets against the six corresponding reference genomes identified in GenBank. As shown in Figure 3, the distribution pattern of mapped reads across each genome was similar for each matched pair of samples indicating that DNA extraction method did not appear to skew sequence distribution. Similarly, the percentage of reads that mapped to its reference was almost identical between each pair of samples. Uniformity of coverage score 


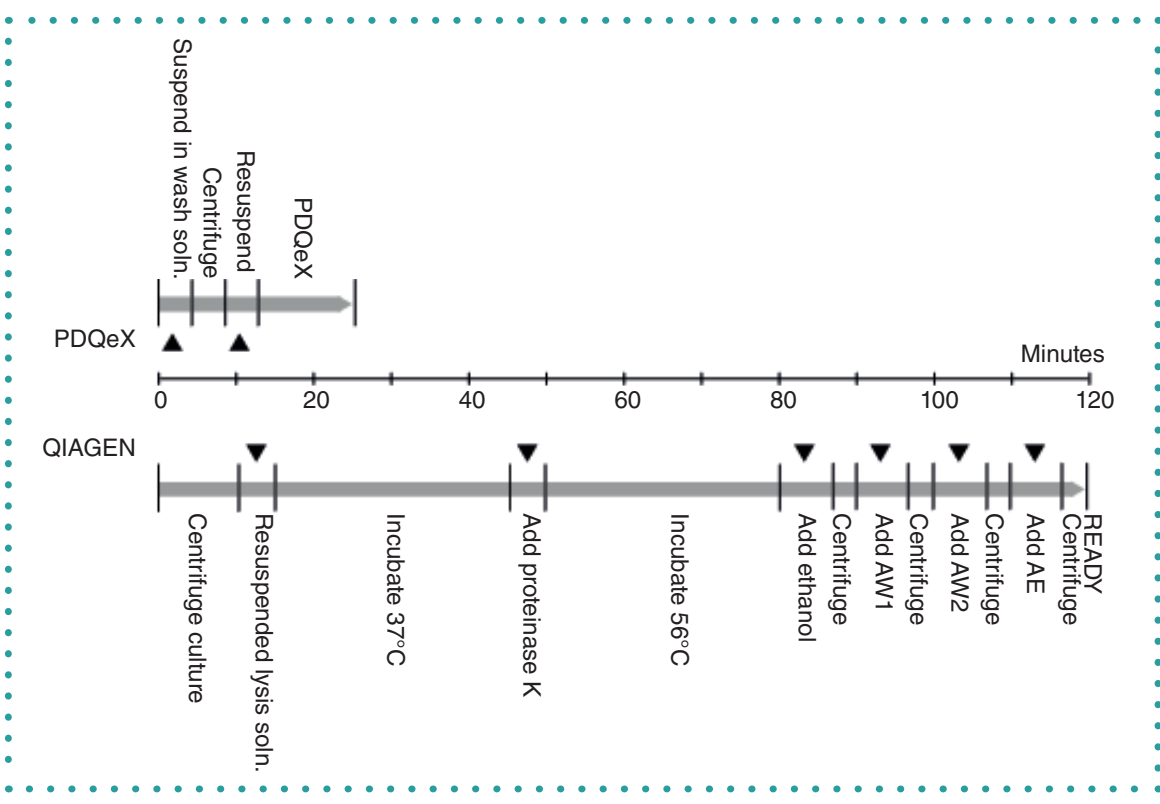

Figure 2. Schematic showing relative processing times and breakdown of the PDQeX and QIAGEN protocols. Black arrows indicate sample transfer or manual addition of reagent.

$\checkmark$ assigned by the Ion Torrent Coverage Analysis Plug-in was also similar between all sample pairs except for M. ruber (PDQeX $77.55 \%$ vs Qiagen $91.59 \%$ ); however, the average depth of coverage was higher for PDQeX (100.5) verses QIAGEN (85.34) for this species.

For DNA pair 1 and 2, approximately $16 \%$ of filtered raw reads mapped to the A. acidocaldarius reference regardless of DNA extraction method, initially suggesting that this sample may not originate from a pure culture. To test this, 200,000 reads from each dataset were used to search against the NCBI nucleotide database, using BLAST+ (version 2.7.1), and program defaults limited to five target sequences per read (-max is a reinvention of DNA purification from sample for use in downstream molecular biology processes. Although rapid, this extraction methodology is effective in both isolating nucleic acids and minimizing enzymatic inhibition as shown in successful qPCR assays [1] [Author, Unpublished Data]. However, as one of the final steps in the PDQeX process involves heating and the $260 / 280$ ratio of extracts deviates from other technologies, the question of whether DNA prepared using this method was suitable for whole-genome sequencing needed to be addressed.

To determine whether PDQeXextracted DNA was compatible with highthroughput sequencing we designed a whole-genome sequencing experiment using six bacterial species with different growth optima, cell wall morphologies and Gram staining status. All sequencing and sequence metrics comparisons were performed blind to DNA extraction method to protect against unconscious bias. In addition, data were reviewed and called by a team of genome scientists not associated with the project with only limited information on each pair of sequence metrics they were asked to score. On all measures of performance tested in this study, DNA produced from the PDQeX system was shown to be comparable to the QIAGEN DNeasy Blood and Tissue extraction kit.

The simplicity of the PDQeX system led to notable advantages over the QIAGEN extraction kit. First, the PDQeX extraction took significantly less time than QIAGEN: 30 min compared with $2 \mathrm{~h}$. In addition, most

\section{Table 2. Code, concentration of extracted samples and references sequences determined following sequence analysis.}

\begin{tabular}{|c|c|c|c|c|c|c|c|}
\hline \multirow[t]{2}{*}{$\begin{array}{l}\text { Bacterial } \\
\text { strain }\end{array}$} & \multicolumn{3}{|c|}{ PDQeX } & \multicolumn{3}{|c|}{ QIAGEN } & \multirow{2}{*}{$\begin{array}{l}\text { Reference sequence determined } \\
\text { post-sequencing }\end{array}$} \\
\hline & Code & Qubit ng/ul & Library Barcode & Code & Qubit ng/ul & Library Barcode & \\
\hline ZCC225 & 1 & 12.5 & 1 & 2 & 2.4 & 2 & $\begin{array}{l}\text { NC_013205.1 Alicyclobacillus acido- } \\
\text { caldarius }\end{array}$ \\
\hline ZCC142 & 3 & 61.8 & 3 & 4 & 61.6 & 1 & $\begin{array}{l}\text { CP003125.1 Geobacillus thermoleo- } \\
\text { vorans }\end{array}$ \\
\hline zcc17 & 5 & 61.8 & 2 & 6 & 41.6 & 3 & NC_006461.1 Thermus thermophilus \\
\hline $\mathrm{ZCC16}$ & 7 & 64.2 & 1 & 8 & 39.4 & 2 & CP011832.1 Geobacillus sp. \\
\hline Zcc14 & 9 & 52.2 & 3 & 10 & 45.8 & 1 & NC_019386.1 Thermus oshimai \\
\hline ZCc12 & 11 & 16.2 & 2 & 12 & 40.8 & 3 & NC_013946.1 Meiothermus ruber \\
\hline
\end{tabular}




\begin{tabular}{|c|c|c|c|c|c|c|c|c|c|c|}
\hline Sample & $\begin{array}{l}\text { Conc. Quant } \\
\text { (ng/ul) }\end{array}$ & $\begin{array}{l}\text { Conc. } \\
\text { Qubit (ng/ } \\
\text { ul) }\end{array}$ & $\begin{array}{l}\text { Starting } \\
\text { material (ng) }\end{array}$ & $\begin{array}{l}\text { Library } \\
\text { pMol }\end{array}$ & $\begin{array}{l}\text { Library av. } \\
\text { size (bp) }\end{array}$ & Barcode & $\begin{array}{l}\text { \# Raw } \\
\text { reads }\end{array}$ & $\begin{array}{l}\text { Mean } \\
\text { read } \\
\text { length }\end{array}$ & $\begin{array}{l}\text { \# Qual- } \\
\text { ity filtered } \\
\text { reads (Q25 } \\
\text { in P40) }\end{array}$ & $\begin{array}{l}\% \text { Post } \\
\text { filtering }\end{array}$ \\
\hline 1 & 5.6 & 13 & 100 & 486 & 392 & 1 & $2,286,908$ & 266 & $2,195,989$ & 96 \\
\hline 2 & 0.7 & 2 & 84 & 418 & 386 & 2 & 444,169 & 238 & 423,677 & 95 \\
\hline 3 & 14.6 & 62 & 100 & 1702 & 385 & 3 & 850,252 & 263 & 820,258 & 96 \\
\hline 4 & 24.5 & 62 & 100 & 1106 & 377 & 1 & $2,194,140$ & 263 & $2,122,642$ & 97 \\
\hline 5 & 19.1 & 62 & 100 & 526 & 375 & 2 & 904,779 & 243 & 870,119 & 96 \\
\hline 6 & 15.3 & 42 & 100 & 488 & 376 & 3 & 573,037 & 243 & 551,192 & 96 \\
\hline 7 & 23.5 & 64 & 100 & 1769 & 375 & 1 & $1,396,965$ & 269 & $1,367,746$ & 98 \\
\hline 8 & 13.0 & 39 & 100 & 4051 & 380 & 2 & $1,537,086$ & 273 & $1,507,369$ & 98 \\
\hline 9 & 15.3 & 52 & 100 & 526 & 359 & 3 & 629,925 & 245 & 612,621 & 97 \\
\hline 10 & 9.7 & 46 & 100 & 3093 & 370 & 1 & 810,075 & 250 & 785,256 & 97 \\
\hline 11 & 7.6 & 16 & 100 & 1487 & 349 & 2 & $1,391,370$ & 234 & $1,351,670$ & 97 \\
\hline 12 & 19.6 & 41 & 100 & 3867 & 365 & 3 & $1,073,411$ & 254 & 1,047,102 & 98 \\
\hline
\end{tabular}

of the processing time for the PDQeX was hands-off as, once sample was added to the PDQeX extraction tube, it was simply incubated with no further manipulations required. Second, the reduction in handling and pipetting steps made the PDQeX easier to use and reduced the potential for sample contamination. Whole-genome sequencing is critically dependent on the character of the DNA sample. Anything that reduces the potential for sample cross-contamination enhances the value of the overall outcome.

Only one of the sequence data sets failed to de novo assemble due to time-out of the bioinformatics computing system we used. This was Coded Sample 1 from bacteria ZCC225 A. acidocaldarius. Sequence data from its pair, Coded Sample 2 could be assembled. It is significant that the sequencing library made from Sample 2 started with less DNA (84 ng compared with $100 \mathrm{ng}$ for all other libraries) and that this was reflected in a lower number of reads following sequencing $(423,677$ vs $2,195,989)$. When data sets from Sample 1 and 2 were mapped against a reference, the same low proportion of reads $(-16 \%)$ mapped to NC_013205.1. We undertook a metagenomic analysis on a subset of Sample 1 and 2 sequences using BLAST and the taxonomic classifi-

Table 4. De novo assembly statistics and blind dataset evaluation.

\begin{tabular}{|c|c|c|c|c|c|c|c|c|c|}
\hline Code & \% Not Incl. & Cont. & Cont. $\geq 1000$ & Max length (bp) & N50 (bp) & Cont. $\geq$ N50 & Group $A^{\dagger}$ & Group $B^{+}$ & $\% \mathbf{P}$ or $\mathbf{Q}$ \\
\hline 3 & 0.5 & 2560 & 335 & 108,604 & 20,594 & 63 & 10 & 16 & $87 \% \mathrm{P}$ \\
\hline 4 & 0.5 & 9530 & 507 & 152,547 & 993 & 512 & 4 & 0 & $13 \% \mathrm{Q}$ \\
\hline 5 & 0.7 & 3593 & 395 & 34,370 & 4786 & 168 & N/A & 13 & $81 \% \mathrm{P}$ \\
\hline 6 & 0.5 & 5134 & 1348 & 25,383 & 1749 & 608 & N/A & 3 & $19 \% Q$ \\
\hline 7 & 0.5 & 2496 & 236 & 126,100 & 22,677 & 57 & 10 & 9 & $63 \% \mathrm{P}$ \\
\hline 8 & 0.4 & 2132 & 210 & 92,375 & 23,807 & 57 & 4 & 7 & $37 \% \mathrm{Q}$ \\
\hline 9 & 0.4 & 1897 & 421 & 34,728 & 6052 & 136 & N/A & 2 & $13 \% \mathrm{P}$ \\
\hline 10 & 0.2 & 896 & 164 & 75,136 & 19,503 & 35 & N/A & 14 & $87 \%$ Q \\
\hline 11 & 0.5 & 5897 & 517 & 58,848 & 2538 & 255 & 0 & 0 & $0 \% \mathrm{P}$ \\
\hline 12 & 0.4 & 2756 & 262 & 136,575 & 17,187 & 60 & 14 & 16 & $100 \% \mathrm{Q}$ \\
\hline 1 & - & - & - & - & - & - & - & - & - \\
\hline 2 & 0.3 & 800 & 1726 & 48,107 & 4309 & 20 & - & - & - \\
\hline
\end{tabular}

${ }^{+}$Scoring for each response: Preferred $=2$; Equal preference $=1$; Not preferred $=0$.

Cont.: Contig; N/A: Proportion of quality filtered reads not part of the assembly; $P=P D Q e X$ method, $Q=Q I A G E N$ method. 


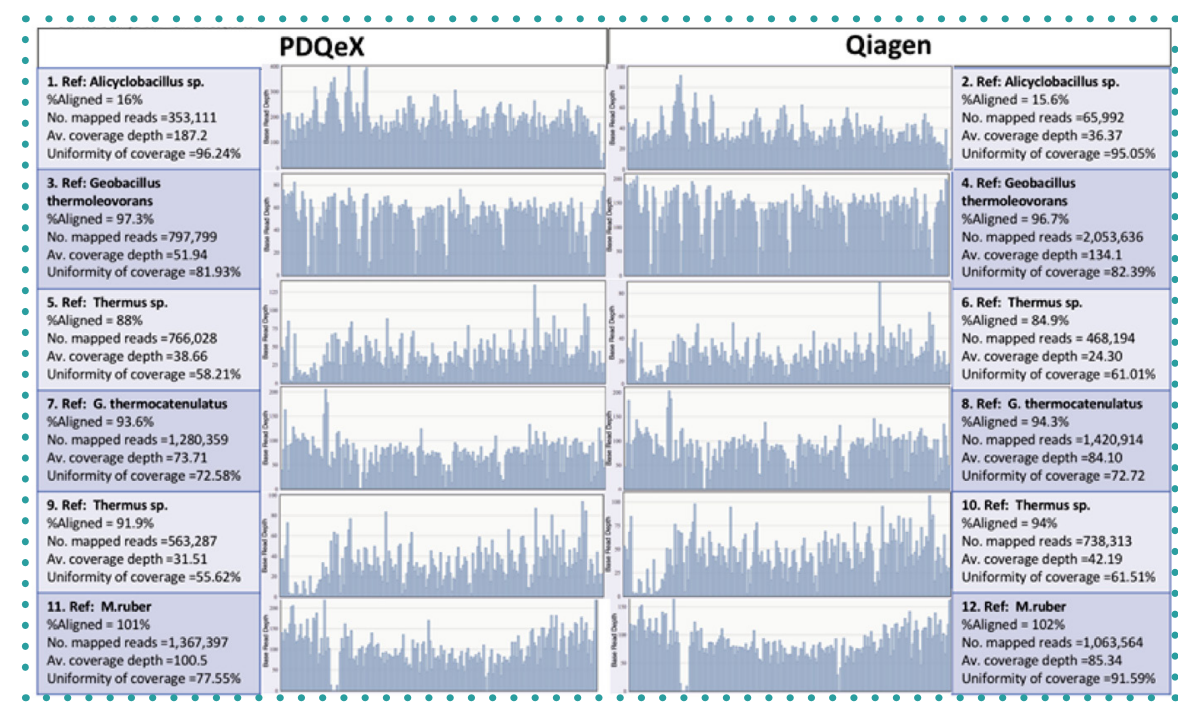

Figure 3. Mapping of bacterial reads to reference genomes using the ion torrent coverage analysis plug-in software tools comparing PDQeX and QIAGEN extraction methods. $X$-axis corresponds to genome position; $Y$-axis is base read depth.

> cation tool MEGAN. Almost all sequences grouped with Alicyclobacillus indicating a pure culture. These findings suggest that ZCC225 is a new species with no other, more closely related organisms currently represented in GenBank.

Bacteria from the ZyGEM NZ Ltd culture collection had originally been identified based on a combination of physical and metabolic characteristics and closest relatives from 16SrDNA sequences [Author, Unpublished data]. We were able to confirm genera in all cases and further refine species identity from whole-genome data. Culture sample ZCC17 (Coded Samples 5 and 6) was originally identified as T. filiformis; however, whole-genome sequencing placed this organism closest to $T$. thermophilus HB8 (NC_006461.1). M. ruber (Coded Samples 11 and 12) was confirmed as closest to reference sequence NC_013946.1; however, there is a clear genomic deletion or insertion evident between the reference and $\mathrm{ZCC} 12$. Work is ongoing to analyze these genomes further.

DNA extracted using the PDQeX system can be used directly for whole-genome sequencing without further purification. DNA obtained using the PDQeX performed as well as DNA produced by more traditional methods, in this case the QIAGEN column purification system. The simplicity and minimal sample manipulation requirement of the PDQeX system make it an attractive option for obtaining DNA samples for highthroughput DNA sequencing studies.

\section{FUTURE PERSPECTIVE}

Sample preparation is key to successful sequencing. Sequencing will be applied to increasingly more biological, commercial and diagnostic problems. The PDQeX is a viable system for preparing quality samples rapidly, cheaply and with minimal chance of sample contamination through reduced operator handling. Its simplicity lends itself to automation and upscaling. In the future, systems like the PDQeX that transform and accelerate sample preparation will become standard in the laboratory. These systems have the capacity to transform fields such as water quality testing, food safety and plant pathology to name a few. In addition, new, more simple and reliable methods for extracting nucleic acids from a sample are required to facilitate molecular testing at the point-of-care and in-field (point-of-need). We see development of new in-lab and point-ofneed applications accelerating in the next 5 years.

\section{AUTHOR CONTRIBUTIONS}

Jo-Ann L Stanton: Designed the study, polled scientists for data preference, funded and supervised the work, drafted the manuscript. Abishek Muralidhar: Prepared bacterial cultures, optimized and performed DNA extractions, coded samples, edited the manuscript. Christy J Rand: Quantified the DNA, performed lonTorrent sequencing and bioinformatics analysis, edited the manuscript. David J Saul: Supervised preparation of bacterial cultures, invented the PDQeX system, edited the manuscript.

\section{ACKNOWLEDGMENTS}

Thanks to Dr Ari Samaranayaka, Biostatistics Unit, Dunedin School of Medicine, University of Otago for statistical analysis and Dr Hugh Cross, Department of Anatomy, University of Otago, for bioinformatics assistance.

\section{FINANCIAL \& COMPETING INTERESTS DISCLOSURE}

This work was funded by Smart Ideas Grant U00X1507, Ministry for Business, Innovation and Employment, New Zealand. Muralidhar and Saul are employees of ZyGEM NZ Ltd. The authors have no other relevant affiliations or financial involvement with any organization or entity with a financial interest in or financial conflict with the subject matter or materials discussed in the manuscript apart from those disclosed.

No writing assistance was utilized in the production of this manuscript.

\section{OPEN ACCESS}

This work is licensed under the AttributionNonCommercial-NoDerivatives 4.0 Unported License. To view a copy of this license, visit http://creativecommons.org/licenses/ by-nc-nd/4.0/

\section{SUPPLEMENTARY DATA}

To view the supplementary data that accompany this paper please visit the journal website at: www.future-science. com/doi/suppl/10.2144/btn-2019-0006

\section{REFERENCES}

1. Holmes AS, Roman MG, Hughes-Stamm S. In-field collection and preservation of decomposing human tissues to facilitate rapid purification and STR typing. Forensic Sci. Int. Genet. 36, 124-129 (2018).

2. Lounsbury JA, Coult N, Miranian DC et al. An enzyme-based DNA preparation method for application to forensic biological samples and degraded stains. Forensic Sci. Int. Genet. 6(5), 607-615 (2012).

3. Saul DJ. WO/2016/144192 (2016).

4. Huson DH, Beier S, Flade I et al. MEGAN Community Edition - interactive exploration and 2 analysis of largescale microbiome sequencing data. PLoS Comput. Biol. 12(6), e1004957 (2016). 